\title{
HELICOBACTER PYLORI INFECTION; COMPARISON OF STOOL ANTIGEN TEST AND HISTOLOGY OF ENDOSCOPIC BIOPSY FOR DIAGNOSIS \\ irfanyounis7887@gmail.com
}

1. MBBS,

FCPS Trainee Gastroenterology Military Hospital, Rawalpindi

2. MBBS, MD gastroenterology

Assistant Professor of

Gastroenterology

Nawaz Sharif Medical College,

University of Gujrat

3. Consultant Gastroenterologist

Military Hospital, Rawalpindi.

4. MBBS, FCPS Medicine

Assistant Professor of Medicine

Nawaz Sharif Medical College,

University of Gujrat

5. MBBS, FCPS Medicine

FCPS Gastroenterology

Associate Professor of Medicine

Gujranwala Medical College

\section{Correspondence Address:}

Dr. Irfan Younus

House No.10, Doctors colony,

Aziz Bhatti Shaheed Teaching

Hospital,

Bhimbar road Gujrat

irfanyounis7887@gmail.com

Article received on:

18/05/2016

Accepted for publication:

30/08/2016

Received after proof reading:

07/10/2016

\section{INTRODUCTION}

Many gastro-intestinal diseases like gastritis, duodenitis, peptic ulceration, gastric malignancies and gastric mucosa-associated lymphoid tissue (MALT) lymphoma are caused by Helicobactor pylori infection. ${ }^{1,2,3}$ The diagnosis of $\mathrm{H}$. pylori is a basic component in the management of these gastro-intestinal problems. Helicobacter pylori infection can be diagnosed through several invasive and non-invasive methods. Endoscope is used in invasive methods which include histopathology, culture, smear examination and rapid urease test or CLO (compylobactor like organism) test. Noninvasive tests include serological testing, stool for H.pylori antigen (HpSA) detection and urea breath testing. ${ }^{4}$

Among them histological examination of endoscopic biopsy has highest sensitivity and specificity. ${ }^{5}$ But many factors are involved in this procedure that can alter the results like the experience of endoscopist, number, site and size of biopsies, methods of staining and interpretation of pathologist. Although histopathalogy is assumed as the gold standard for the detection of Helicobactor pylori ${ }^{5}$ but due to its high cost, non-availability of endoscope and the need for properly trained personnel, it may not be routinely used in clinical practice.

That's why we required a diagnostic tool for detection of $\mathrm{H}$.pylori which should be noninvasive, easier to perform, cost effective, quick and suitable for follow ups, does not require specialized expertise and performed easily in all laboratories. Detection of H.pylori antigen in the stool of the patient is an excellent tool for diagnosing this infection ${ }^{6}$ and fulfills all the above mentioned criteria. In addition, many studies showed that the results of HpSA are 
comparable with histology for diagnosis of H.pylori infection. ${ }^{7,8,9,10}$ All these studies are done outside Pakistan, that's why we tried to compare the efficacy of these test in our local population which will be helpful for patients, clinician and making our local guidelines.

\section{MATERIALS AND METHODS}

The study was cross sectional validation type and carried out in the department of Gastroenterology, Military Hospital, Rawalpindi from $1^{\text {st }}$ November 2014 to $30^{\text {th }}$ April 2015. One hundred and ten patients were selected through non-probability consecutive sampling technique. Informed consent was taken from each individual after explaining the aim of study. Adults between 18 to 60 years (both males and females) presenting with dyspepsia who did not respond to 6 weeks trial of Proton pump inhibitors (PPI) or having alarm symptoms i.e, weight loss, anemia, dysphagia or blood in the stool were included in study. While the treatment experienced patients were excluded from the study. All the patients underwent esophageogastroduodenoscopy, three antral biopsies taken put in formalin and sent to Military Hospital labortary, and examined for H.pylori by pathologists. H.pylori was considered positive if it was identified on histological examination. A fresh stool sample was also collected from each patient and sent to hospital laboratory. Results were recorded in a preformed well-designed Performa. Information was entered and analyzed by utilizing SPSS 16.0. Frequency and percentages were calculated for qualitative variables like gender, H.Pylori Stool Antigen and histopathology. Quantitative variable like age was mentioned as Mean \pm standard deviation. $2 \times 2$ Table was used to calculate sensitivity, specificity and predictive values either positive or negative.

\begin{tabular}{|c|c|c|}
\hline & $\begin{array}{c}\text { Histology } \\
\text { Positive }\end{array}$ & $\begin{array}{c}\text { Histology } \\
\text { Negative }\end{array}$ \\
\hline Stool H.Pylori Positive & (a) & (b) \\
\hline Stool H.Pylori Negative & (c) & (d) \\
\hline $2 \times 2$ Table for Calculating Diagnostic Accuracy of \\
HPSA
\end{tabular}

(a) True Positives; (b) False Positives;

(c) False Positives;

(d) True Negatives.

- Sensitivity: $a / a+c \times 100$

- Specificity: $d / d+b \times 100$

- PPV: $\quad \mathrm{a} / \mathrm{a}+\mathrm{b} \times 100$

- NPV: $\quad \mathrm{d} / \mathrm{c}+\mathrm{d} \times 100$

\section{RESULTS}

Study composed of 110 paients, among them 80 were males (72.2\%) and 30 females (27.27\%). the mean and standard deviation of age was observed as $33 \pm 16 y r$ (range: 18-60yrs). Three participants were excluded due to refusal from performing endoscopy just before start of procedure. Eighty (74.76\%) out of 107 patients were positive for both histology and H.pylori stool antigen test. Eighty two (76.63\%) patients had positive HpSA while it was negative in 28 (26.16\%). Histopathological diagnosis was made in $83(77.57 \%)$ patients. The sensitivity and specificity were $96.3 \%$ and $91.66 \%$ respectively. Positive predictive value was in $97.56 \%$ while $88 \%$ had negative predictive value for $\mathrm{H}$.pylori stool antigen test. Overall the diagnostic accuracy of this test was $94.4 \%$ for detection of infection.

\begin{tabular}{|l|c|c|}
\hline & $\begin{array}{c}\text { Histology } \\
\text { Positive }\end{array}$ & $\begin{array}{c}\text { Histology } \\
\text { Negative }\end{array}$ \\
\hline Stool H.pylori Test Positive & $80(a)$ & $2(b)$ \\
\hline Stool H.pylori Test Negative & $3(c)$ & $22(d)$ \\
\hline
\end{tabular}

Table-I. " $2 \times 2$ " table for calculating diagnostic accuracy of stool h.pylori test for diagnosing h. Pylori infection

- Sensitivity: $80 / 80+3 \times 100=96.3$

- Specificity: $22 / 22+2 \times 100=91.66$

- PPV: $80 / 80+2 \times 100=97.56$

- NPV: $22 / 3+22 \times 100=88$

- Diagnostic accuracy $=80+22 / 80+22+2+3=$ 94.4\%

\section{DISCUSSION}

In the present study endoscopic antral biopsy and patient's stool for $\mathrm{H}$. pylori antigen (HpSA) test were utilized as diagnostic tools and then results were compared keeping histopathology as gold standard. 


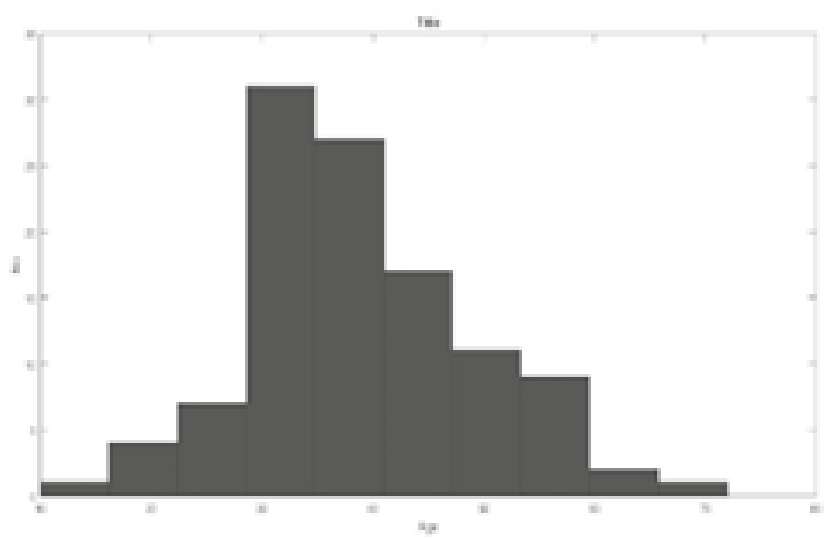

Figure-1. Age of the patients, majority (30-50years)

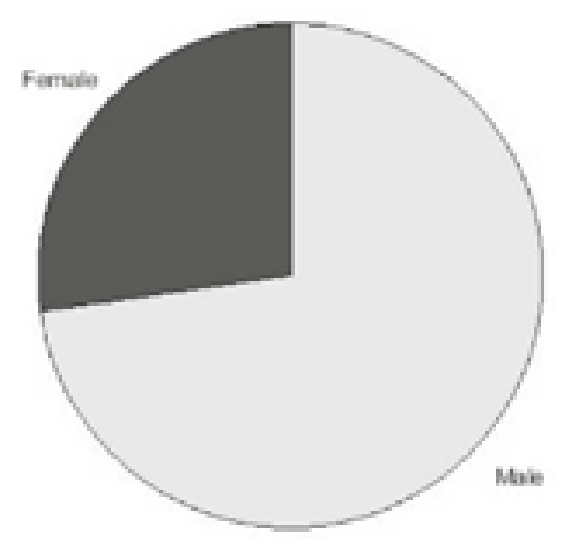

Figure-2. Gender distribution

Results showed that the histological test was mildly more accurate than $\mathrm{H}$.pylori stool antigen test. HpSA had diagnostic accuracy of $94.4 \%$ for detection of this infection. The sensitivity and specificity of stool for H.pylori test in comparison to histopathological diagnosis was $96.3 \%$ and $91.66 \%$ respectively in our study.

Our results were similar to many universal studies like Trevisani et $\mathrm{al}^{11}$, they concluded that in treatment naïve patients $\mathrm{H}$.pylori stool antigen test is an accurate tool for diagnosis of H.Plori infection. They used Rapid urease test (RUT) from gastric biopsies (invasive method) and H.pylori stool antigen test (non-invasive method) for detection of H.Pylori. Results showed that HpSA had $94 \%$ sensitivity and $90 \%$ specificity. In another study $\mathrm{Li}$ et $\mathrm{al}^{12}$ demonstrated that HpSA was reliable, simple to perform and painless test for detection of H.pylori infection. It was $92.6 \%$ sensitive and $88.5 \%$ specific while diagnostic accuracy was $90.6 \%$.

In a study conducted by Vaira et $\mathrm{al}^{13}$ on treatment naïve patients, HpSA had sensitivity of $94 \%$ and specificity $92 \%$ for $\mathrm{H}$.pylori detection. They analysed different results from variable tests like $\mathrm{H}$. Pylori stool antigen tests, gastric biopsies for H.Pylori histology as well as culture, rapid urease test (RUT) and urea breath test. Almost similar results were found in a study by Tanaka et $\mathrm{al}^{14}$, they found HpSA test useful and accurate for the rapid detection of Helicobactor pylori infection. In this study researchers made comparison of non-invasive test like HpSA with invasive tests like biopsy, culture and Rapid urease test (RUT). Results showed that the HpSA test was $98.3 \%$ sensitive and $95 \%$ specific.

In Pakistan Baqai et $\mathrm{al}^{15}$ conducted a study on 43 treatment naïve patients in Karachi. Comparison was made between non- invasive methods like HpSA test and H.pylori IgG serology with an invasive test i.e. Campylobacter like organism (CLO) test. The sensitivity and specificity of H.pylori stool antigen test in this study was $65 \%$ and $76 \%$ respectively. This difference may be due to small sample size of the study, different testing techniques or dissimilar inclusion criteria.

\section{CONCLUSION}

We concluded that HpSA is an accurate, economical, painless, quick and easily performed test and as reliable as histopathology which is expensive, slow, requires team, difficult to perform and not available everywhere. It can be considered as a noninvasive first-line routine diagnostic test in our region.

Copyright@ 30 Aug, 2016.

\section{References}

1. Yakoob J, Abid S, Abbas Z, Jafri W, Ahmad Z, Ahmed $R$, Islam M. Distribution of Helicobacter pylori virulence markers in patients with gastroduodenal diseases in Pakistan. BMC Gastroenterol. 2009; 9:87.

2. Parsonnet J, Hansen S, Rodriguez L, et al. Helicobacter pylori infectionand gastric lymphoma. N Engl J Med 1994;330:1267-71.

3. Wotherspoon AC. Helicobacter pylori infection and 
gastric lymphoma. Br Med Bull 1998;54:79-85

4. Vilaichone RK, Machchai V, Graham DY. Helicobacter pylori: diagnosis and management. Gastroenterol Clin North Am2006; 35: 228-47.

5. Lin MH, Cheng HT, Chuang WY, Yu LK, Tsou YK, Lee MS. Histological examination of ulcer margin for diagnosing Helicobacter pylori infection in patients with gastriculcers. Ann Diagn Pathol. 2013; 1 7:63-6.

6. Chehter EZ, Bacci MR, Fonseca FL, Gonçalves JA, Buchalla G, Shiraichi SA, et al. Diagnosis of the infection by the Helicobacter pylori through stool examination: Method standardization in adults. Clin Biochem. 2013 Jun 12

7. Pilar Grino, Sonia Pascuala, Jose Sucha, Juan A. Casellas,et al. Comparison of stool immunoassay with standardmethods for detection of Helicobacter pylori infection in patients with upper-gastrointestinal bleeding of peptic origin. Eur J Gastroenterol Hepatol 2003; 15: 525-529.

8. Vaira D, Vakil N. Blood, urine, stool, breath, money, and Helicobacter pylori. Gut. 2001; 48:287-289.

9. Gisbert JP, Pajares JM. Stool antigen test for the diagnosis of Helicobacter pylori infection: a systematic review. Helicobacter. 2004;9:347-368
10. Kazemi S, Tavakkoli H, Habizadeh MR, Emami $\mathrm{MH}$. Diagnostic values of Helicobacter pylori diagnostic tests: stool antigen test, urea breath test, rapid urease test, serology and histology. J Res Med Sci. 2011; 16:1097-104.

11. Trevisani L, Sartori S, Galvani F, Rossi MR, RuinaM, Chiamenti $C$, et al. Evaluation of a new enzyme immunoassay for detecting Helicobacter pylori in feces: A prospective pilot study. Am J Gastroenterol 1999; 94(7):1830-3

12. Li $Y$, Guo $H$, Zhang $P$, Zhao $X$, Da S. Clinical value of Helicobacter pylori stool antigen test, immunoCardStat $\mathrm{HpSA}$, for detecting $\mathrm{H}$. pylori infection. World J Gastroenterol 2004; 10(6):913-4

13. Vaira D, Malfertheiner $P$, Megraud F, Aon ATR,Deltenre M, Hirschl AM, et al. Diagnosis of Helicobacter pylori infection with a new non-invasive antigen based assay. Lancet 1999; 354:30-3.

14. Tanaka A, Watanabe K, Tokunaga K, Hoshiya S,Imase $\mathrm{K}$, Sugano $\mathrm{H}$, et al. Testing for Helicobcterpylori stool antigen test before and after eradicationtherapy. $J$ Gastroenterol Hospital 2003; 18:732-8.

15. Baqai R, Qureshi H, Arian G, Mehdi I. Diagnostic efficacy of stool antigen test (HPSA), CLO test and serology for the detection of Helicobacter pylori infection. J Ayub Med Coll Abbott bad 2003; 15(4):346.

\section{PREVIOUS RELATED STUDY}

Farid Imanzadeh, Amir Imanzadeh, Ali Akbar Sayyari, Mehrnosh Yeganeh, Hazhir Javaherizadeh, Bizhan Hatamian. HELICOBACTER PYLORI INFECTION; IN CASES WITH AND WITHOUT SUBJECTIVE HALITOSIS (Original) Prof Med Jour 17(4) 543-545 Oct, Nov, Dec 2010.

Qurban Ali Khaskheli, Saleem A Kharal, Anjum Syed, Qazi Muhammad Rizwan, Muhammad Asif Durrani. SERODIAGNOSIS OF HELICOBACTER PYLORI INFECTION (Original) Prof Med Jour 9(2) 145-153 Apr, May, Jun, 2002.

\section{AUTHORSHIP AND CONTRIBUTION DECLARATION}

\begin{tabular}{|c|c|c|c|}
\hline Sr. \# & Author-s Full Name & Contribution to the paper & Author $=\mathbf{s}$ Signature \\
\hline 1 & Dr. Adnan Qadir & $\begin{array}{l}\text { Concept and design of } \\
\text { study }\end{array}$ & esen \\
\hline 2 & Dr. Irfan Younis & $\begin{array}{l}\text { Data collection, Statistics, } \\
\text { Manuscript writing }\end{array}$ & \\
\hline 3 & Brig. Dr. Shahid Raza Khalid & Critical revision of article & \\
\hline 4 & Dr. Zamir Butt & Data collection & \\
\hline 5 & Dr. Shahid Sarwar & Drafting of articles & \\
\hline
\end{tabular}

